\title{
Tripled semitendinosus with single harvesting is as effective but less invasive compared to standard gracilis-semitendinosus harvesting
}

\author{
Luca Drocco \\ Daniele Camazzola \\ Riccardo Ferracini \\ Sebastien Lustig \\ Laura Ravera \\ Eugenio Graziano \\ Alessandro Massè \\ Alessandro Bistolfi
}

Department of Orthopaedics, Traumatology and Rehabilitation, Hospital "Città della Salute e della Scienza”, Trauma Center, Turin, Italy

Corresponding author:

Alessandro Bistolfi

Department of Orthopaedics, Traumatology

and Rehabilitation

Hospital "Città della Salute e della Scienza",

Trauma Center

Via Zuretti 29

10126 Turin, Italy

E-mail: abistolfi@cittadellasalute.to.it

\section{Summary}

Introduction: The anterior cruciate ligament (ACL) reconstruction with pes anserinus tendons has been increasingly used throughout the last years. Although less invasive compared to other autologous grafts, a reduction of internal rotation and flexion strength after gracilis and semitendinosus harvesting has been reported. Harvesting one tendon instead of two from the pes anserinus can reduce the deficit of the knee flexor strength and improve the functional recover without weakening the reconstructed ligament.

Methods: Forty-five (45) patients who had ACL reconstruction with triple semitendinosus graft (ST3) have been compared with other 45 similar patients who had ACL reconstruction with double gracilis-semitendinosus tendons (GST). Patients have been evaluated at a minimum of 12 months after surgery: IKDC scale, KT-1000, One Leg Hop Test for the objective stability; Isokinetic test for the strength; Tegner scale, Lysholm and IKDC subjective evaluation form for the function.

Results: No differences have been detected between the groups for the objective item assessed.
Male patients' subjective IKDC score was statistically better for the ST3 group. Recreational soccer players showed a higher Lysholm and subjective IKDC score in ST3 group compared to GST group. There was no difference regarding the return to sport.

Conclusion: ST3 guarantees the same objective knee stability compared to a GST. It is a viable option for ACL reconstruction that allows a better preservation of patient's anatomy and a less invasive harvesting surgery.

Level of evidence: III b, case control study.

KEY WORDS: anterior cruciate, triple semitendinosus, graft, reconstruction.

\section{Introduction}

Recently, the pes anserinus tendons, particularly the gracilis and the semitendinosus, are amongst the most frequently used grafts in primary anterior cruciate ligament reconstruction ${ }^{1,2}$; one of the main reasons is the pain reduction and minor anterior knee discomfort in comparison to patellar tendon (BTB) ${ }^{3-5}$. Since the hamstrings muscles contribute to knee flexion and internal rotation of the thigh, several Authors hypothesized that harvesting these tendons may cause a strength reduction in knee flexion ${ }^{6,7}$, especially in the deepest angle of flexion ${ }^{8}$. Therefore, the use of a single tendon for graft preparation has been proposed especially for those athletes who require the highest levels of flexion strength and a faster recovery ${ }^{9}$.

The aim of this study was to compare the clinical and functional results in primary ACL reconstruction using graft prepared with the semitendinosus alone, in a tripled configuration (ST3) and a doubled gracilissemitendinosus graft (GST). Primary endpoints evaluated were: objective stability, muscle strength recovery, subjective stability, global knee function and return to sport.

\section{Materials and methods}

Among the 239 patients operated for ACL reconstruction from 2012 to 2014, 45 patients had a ST3 graft. These 45 patients were compared with a control group of 45 patients that underwent ACL reconstruction in the same period of time with GST; the patients 
Tripled semitendinosus with single harvesting is as effective but less invasive compared to standard gracilis-

semitendinosus harvesting

have been selected to be homogenous in terms of age, sport, associated lesion, and activity level. The inclusion criteria for both groups have been: primary ACL reconstruction, absence of other ligamentous injuries, no previous anterior cruciate ligament reconstruction on contralateral knee, athletes either competitive and non-professional. Figure 1 summarizes the construction of the two groups.

\section{Surgical technique}

\section{Grafts preparation}

Through a $3-5 \mathrm{~cm}$ oblique incision in the skin projection of pes anserinus tendons the gracilis and semitendinosus tendons were identified and prepared for harvesting. In the GST control group both tendons were harvested individually and then measured and prepared on the back table. The two structures were duplicated to form a bundle of fours layers; the proximal end was sutured for $3 \mathrm{~cm}$ with a thin resorbable wire and the four distal tails were sutured separately with differently colored resorbable wires. Finally, a strong non resorbable wire was finally inserted in the proximal end to allow the positioning of the graft. In the ST group only the semitendinosus tendon was harvested and prepared after measurement. The tendon was folded into three strands, forming a proximal end formed by a loop that contains one of the two extremities, while the distal end was composed by the other extremity and a distal double stranded loop. As well as the GST graft, the extremities were first united for $3 \mathrm{~cm}$ with resorbable thin wire and a non resorbable strong wire was placed to allow the traction of the graft. The distal ends were sutured respectively for traction and tractionunion with a non-absorbable strong wire. According to surgical technique, the minimum semitendinosus length necessary to construct the triple semitendinosus is 240 $\mathrm{mm}$. Figure 2 shows the preparation of the tendons.

\section{Graft positioning}

For both groups, the tibial tunnel was positioned with a $55^{\circ}$ angle to the coronal plane and $30^{\circ}$ angle to the tibial axis. The femoral tunnel was drilled with the trans-tibial technique. In all 90 cases, the femoral fixation was performed with the RigidFix ${ }^{\circledR}$ (DePuy Syntes) transverse fixation system. Tibial fixation re-

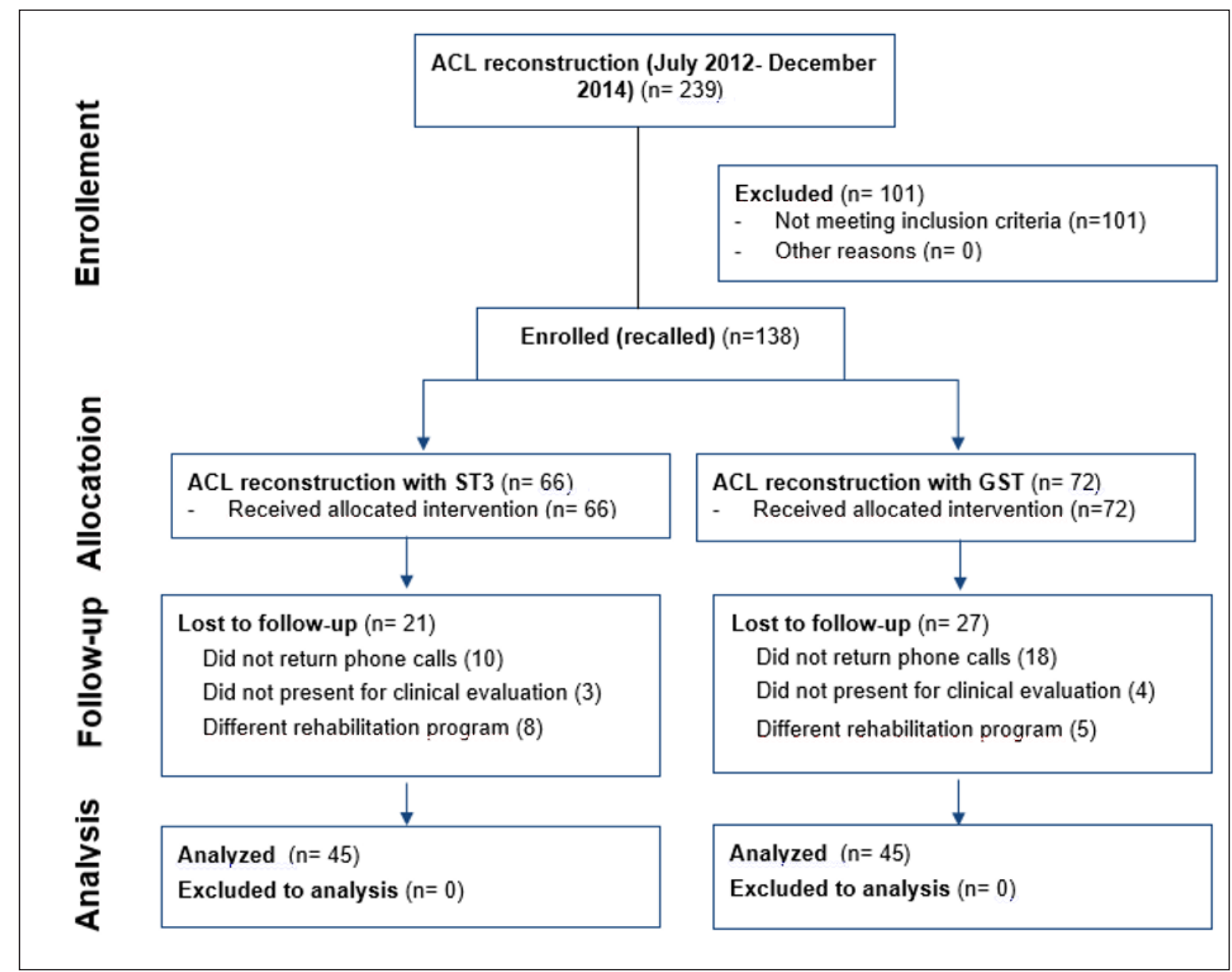

Figure 1. Selection of the two groups. 


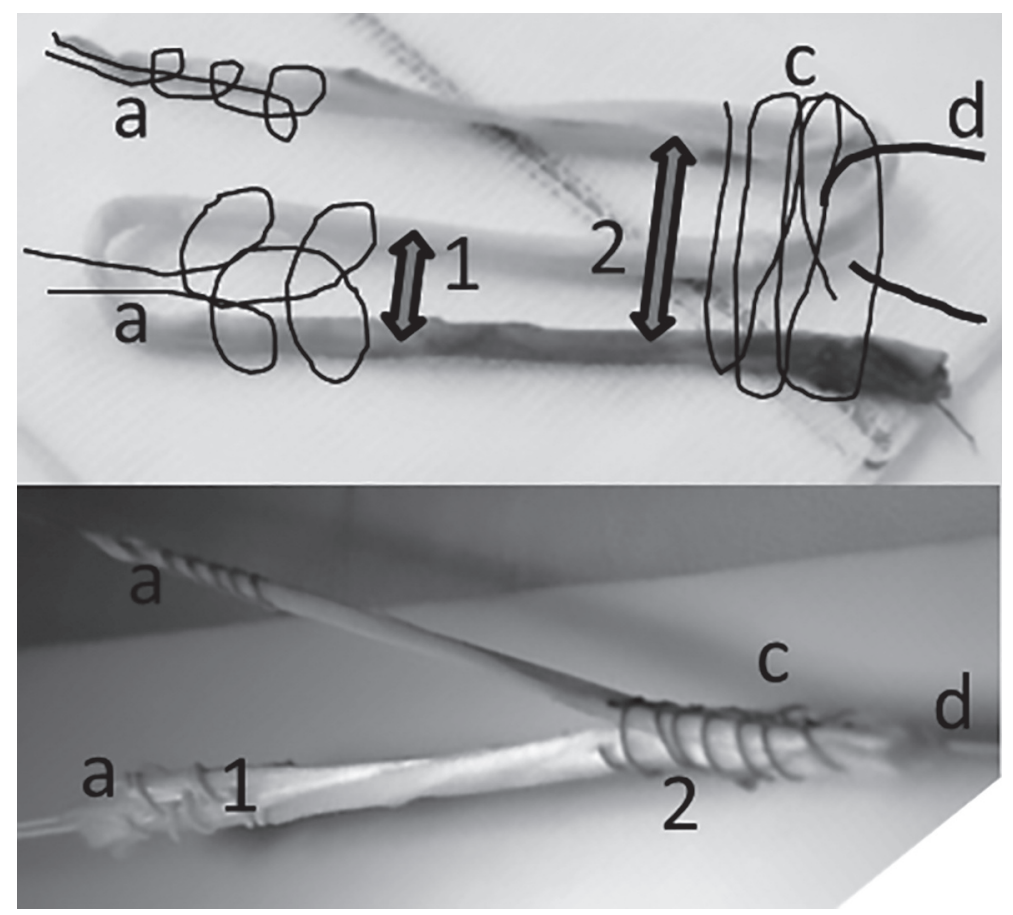

Figure 2. ST3 preparation. 1) Doubled part: a. non resorbable wire (caliber 2) for tibial traction (single extremity) and traction and union (doubled extremity); 2 tripled part: c. $3 \mathrm{~cm}$ with resorbable wire (caliber 2-0); d. non re-absorbable wire for traction of the graft (caliber 2 or armed wire). The minimum length of the harvested tendon necessary to construct the triple semitendinosus (ST3) is $240 \mathrm{~mm}$.

quired the use of a system with bio-resorbable screw with shell (BIOINTRAFIX®, DePuySyntes). The tibial and femoral tunnel diameters reflect the thickness of the graft: these measurements were collected and compared between the two groups.

\section{Clinical evaluation}

\section{Objective stability}

It has been assessed during the routine follow-up controls (12-30 months, mean follow-up: ST3 group: 22.6 \pm 7.7 moths; GST group $23.0 \pm 7.3$ months). Clinical examination was executed according to IKDC Knee Ligament Evaluation Form (IKDC). The side-toside difference in antero-posterior laxity was measured with the Arthrometer KT-1000 (MEDmetric, San Diego, CA). The One-Leg-Hop Test was performed to evaluate the dynamic stability and the level of confidence in the operated knee.

\section{Muscle strength recovery}

The isokinetic test was applied bilaterally at the sixth month postoperatively using the Biodex multi-joint system (Biodex ${ }^{\circledR}$, Shirley, NY), with the patient seating at the angular speed of $90^{\circ}, 180^{\circ}$ and $240^{\circ}$ persecond. Test was performed five times for each angular speed and the best result was considered. The test analyzed strength deficit of operated limb in knee flexion and extension expressed as Peak of Torque $(\mathrm{NxM})$. Deficit was expressed as a percentage involved/non-involved limb: the "+" sign indicates a deficit in strength muscle in the involved limb, while a "-" sign indicates a deficit in strength muscle in the non-involved limb.
Return to sport and subjective stability

Tegner scale, Lysholm and IKDC Subjective Evaluation Form have been used during the clinical evaluation to assess the activity level, the sensation of stability and the global knee function.

\section{Compliance with ethical standards}

Patients gave their consent, the study was authorized by the local Institutional Revision Board (IRB) in accordance with the ethical standards.

The Authors declare that the study meets the ethical standards of the journal MLTJ ${ }^{10}$.

\section{Statistical analysis}

The collected data were processed with STATA ${ }^{\circledR}$ 12.0 (StataCorp, Texas). To analyze normally distributed quantitative variables it has been performed the parametric $t$-Student test. For the nonparametric test it was used the Mann-Whitney $U$-test. Differences were considered significant if $p$-value was $<0.05$.

\section{Results}

Table I shows the characteristic of ST3 group and control GST group. There was no difference in terms of sex, age, height, weight, BMI and practiced sports and associated lesion between the two populations.

\section{Tunnel diameters}

In the ST3 group the mean intraoperative tibial tunnel diameter was $8.70 .9 \mathrm{~mm}$, while in the GST groups was $8.4 \pm 0.8 \mathrm{~mm}$; the mean intraoperative femoral diameters were: $8.2 \pm 0.8 \mathrm{~mm}$ for the ST3 group and 8.3 
Tripled semitendinosus with single harvesting is as effective but less invasive compared to standard gracilissemitendinosus harvesting

Table I. Distribution of sports partook and demographic and anthropometric characteristics of the two groups. "Others" sport include (rugby, martial arts, tennis, running). ST3, tripled semitendinosus; GST, gracilis + semitendinosus; BMI, body mass index; Data are reported in mean \pm SD.

\begin{tabular}{|c|c|c|c|}
\hline & ST3 & GST & $p$ \\
\hline Patients & 45 & 45 & \\
\hline Sex (Male) & $34(76 \%)$ & $27(60 \%)$ & 0.13 \\
\hline age [years] & $29.5 \pm 10.0$ & $27.7 \pm 9.0$ & 0.44 \\
\hline weight $[K g]$ & $71.2 \pm 10.9$ & $69.7 \pm 13.7$ & 0.61 \\
\hline height $[\mathrm{cm}]$ & $174.6 \pm 7.1$ & $172.08 \pm 10.01$ & 0.23 \\
\hline BMI & $23.3 \pm 2.8$ & $23.2 \pm 2.9$ & 0.94 \\
\hline ASSOCIATED LESION & & & U-test \\
\hline Medial meniscal tear & 26 & 23 & \\
\hline Partial meniscectomy & 11 & 9 & \\
\hline Meniscal repair & 15 & 14 & \\
\hline Lateral meniscal tear & 9 & 10 & \\
\hline Partial meniscectomy & 6 & 6 & \\
\hline Meniscal repair & 3 & 4 & \\
\hline Other lesion & 0 & 2 & \\
\hline No other lesion & 13 & 12 & \\
\hline & & & 0,94 \\
\hline SPORT & & & U-test \\
\hline Soccer & $18(40 \%)$ & $18(40 \%)$ & \\
\hline Ski & $12(26.7 \%)$ & $8(17.8 \%)$ & \\
\hline Basket & $3(6.67 \%)$ & $1(2.3 \%)$ & \\
\hline Volleyball & $0(0 \%)$ & $8(17.8 \%)$ & \\
\hline \multirow[t]{2}{*}{ Others } & $12(26.7 \%)$ & $10(22.2 \%)$ & \\
\hline & & & 0.75 \\
\hline
\end{tabular}

$\pm 0.8 \mathrm{~mm}$ for the GST group. No statistically significant difference was assessed between the two groups in intraoperative tunnel diameters (tibial tunnel $p=0.16$, femoral tunnel $p=0.55$ ).

Objective stability

IKDC (Lachman and pivot-shift), side-to-side differences in antero-posterior laxity (KT-1000), dynamic stability (One-Leg-Hop) and IKDC class did not reveal any significant difference. Table II shows the results of some IKDC items and the final IKDC class.

Muscle strength recovery

Isokinetic test analysis (Tab. III) did not show any difference in extension or flexion at any speed. A trend of minor peak of torque's deficit in ST3 group can be observed throughout the flexion, in comparison to the GST group (no statistical differences). A strong dispersion of the data was noted inside each group as confirmed by the high values of standard deviation.
Return to sport and subjective stability

Tegner activity level was 7,2 $\pm 1,3$ for ST3 group and $6,9 \pm 1,4$ for the GST control group before injury and $6,2 \pm 1,6$ for the ST3 group and $5,9 \pm 1,2$ for the GST group after surgery: no significant statistical difference between the two groups. A significant difference arose in preinjury Tegner score respect to the post surgery Tegner score for both groups (ST3: $p=$ 0,007; GST: $p=0,0004)$.

Table IV reports the Lysholm and IKDC subjective scores: no statistical difference between the ST3 and GST. A statistical significant difference was observed subdividing the patients for sex and sport partook: male patients had a better IKDC Subjective score in the ST3 group. A significant improvement in the ST3 group was also recorded for soccer players in terms of IKDC and Lysholm scores.

During the clinical assessment just one case of probably re-tear in all 90 patient was documented: a female patient in ST3 group, with symptoms of instability, marked Pivot Shift and a KT-1000 side-to-side difference of 6-10 $\mathrm{mm}$. 
Table II. Test for objective stability. Final results of the IKDC form: A: "normal”; B: "Nearly Normal”; C: "Abnormal”, D: "Severe Abnormal". ST3, tripled semitendinosus; GST, gracilis + semitendinosus.

\begin{tabular}{|c|c|c|c|}
\hline Clinical evaluation & ST3 & GST & $p$ \\
\hline Lachman test & & & 0.77 \\
\hline $1-2 \mathrm{~mm}$ & 22 & 26 & \\
\hline $3-5 \mathrm{~mm}$ & 21 & 19 & \\
\hline $6-10 \mathrm{~mm}$ & 2 & 0 & \\
\hline$>10 \mathrm{~mm}$ & 0 & 0 & \\
\hline Pivot shift & & & 1 \\
\hline Equal & 13 & 12 & \\
\hline Slight & 31 & 32 & \\
\hline Marked & 1 & 0 & \\
\hline Gross & 0 & 0 & \\
\hline KT-1000 & & & 0.76 \\
\hline $1-2 \mathrm{~mm}$ & 22 & 20 & \\
\hline $3-5 \mathrm{~mm}$ & 21 & 23 & \\
\hline $6-10 \mathrm{~mm}$ & 2 & 2 & \\
\hline$>10 \mathrm{~mm}$ & 0 & 0 & \\
\hline One Leg Hop Test & & & 1 \\
\hline $90-100 \%$ & 37 & 29 & \\
\hline $76-89 \%$ & 6 & 14 & \\
\hline $50-75 \%$ & 2 & 2 & \\
\hline$<50 \%$ & 0 & 0 & \\
\hline Final evaluation & & & 0.88 \\
\hline$A$ & 7 & 6 & \\
\hline$B$ & 30 & 33 & \\
\hline C & 8 & 6 & \\
\hline$D$ & 0 & 0 & \\
\hline
\end{tabular}

Table III. Percentage involved/uninvolved of isokinetic strength deficit in the different angular speed performed. Data are reported in mean \pm SD. ST3, tripled semitendinosus; GST, gracilis + semitendinosus.

\begin{tabular}{|c|c|c|c|c|c|}
\hline Extension & ST3 & & GST & $p$ & \\
\hline $90 \% / \mathrm{s}$ & & $15.9 \pm 15.3$ & & $23.9 \pm 12.5$ & 0.12 \\
\hline $180^{\circ} / \mathrm{s}$ & & $11.3 \pm 10.3$ & & $15.4 \pm 9.7$ & 0.27 \\
\hline $240^{\circ} / \mathrm{s}$ & & $10.6 \pm 11.3$ & & $18.4 \pm 12.5$ & 0.08 \\
\hline Flexion & ST3 & & GST & $p$ & \\
\hline $90 \% / \mathrm{s}$ & & $3.8 \pm 15.2$ & & $9.3 \pm 22.7$ & 0.45 \\
\hline $180 \% / \mathrm{s}$ & & $-1.6 \pm 11.3$ & & $3.3 \pm 23.9$ & 0.48 \\
\hline $240 \% / s$ & & $-6.2 \pm 29.3$ & & $5.5 \pm 27.1$ & 0.25 \\
\hline
\end{tabular}

\section{Discussion}

The main finding of this study is that ST3 graft guaranteed the same objective stability compared to GST graft. In addition, ST3 showed better scores in terms of subjective stability and strength in flexion for some patients. Return to sport and activity level have been the same for both grafts. Nevertheless, the activity level was not always restored to the pre-injury level, like already reported in the literature ${ }^{11-13}$. In addition, these results suggested that the mean thickness of the two type of graft did not differ significantly. 
Tripled semitendinosus with single harvesting is as effective but less invasive compared to standard gracilissemitendinosus harvesting

Table IV. Results of Lysholm scale and subjective IKDC Form (basketball and volleyball were not analyzed for the low number of participants). Data are reported in mean \pm SD. ST3, tripled.

\begin{tabular}{|c|c|c|c|}
\hline Subjective Forms & $3 S T$ & GST & $p$ \\
\hline Lysholm & $90.7 \pm 12.9$ & $87.1 \pm 9.7$ & 0.19 \\
\hline Male $(34 ; 27)$ & $92.3 \pm 10.4$ & $89.2 \pm 8.5$ & 0.26 \\
\hline Female $(11 ; 18)$ & $91.0 \pm 9.6$ & $84.1 \pm 10.7$ & 0.16 \\
\hline Soccer $(18 ; 18)$ & $97.7 \pm 3.8$ & $87.0 \pm 9.6$ & ${ }^{\star} 0.002$ \\
\hline Ski $(12 ; 8)$ & $92.7 \pm 9.2$ & $85.8 \pm 15.3$ & 0.29 \\
\hline Others $(12 ; 10)$ & $84.4 \pm 16.3$ & $85.0 \pm 8.7$ & 0.93 \\
\hline IKDC & $85.3 \pm 16.0$ & $78.9 \pm 14.5$ & 0,08 \\
\hline Male $(34 ; 27)$ & $87.1 \pm 11.0$ & $81.2 \pm 12.2$ & ${ }^{\star} 0.04$ \\
\hline Female $(11 ; 18)$ & $87.1 \pm 13.3$ & $75.6 \pm 17.2$ & 0.13 \\
\hline Soccer $(18 ; 18)$ & $91.4 \pm 7.9$ & $79.6 \pm 12.9$ & ${ }^{\star} 0.006$ \\
\hline Ski $(12 ; 8)$ & $87.2 \pm 13.2$ & $82.6 \pm 8.4$ & 0.46 \\
\hline Others $(12 ; 10)$ & $77.2 \pm 22.1$ & $64.0 \pm 17.4$ & 0.21 \\
\hline
\end{tabular}

The graft choice, either the semitendinosus alone or both gracilis and semitendinosus, set in different configurations, is an important concern for primary $A C L$ reconstruction and, although discussed by several Authors, the results tend to be different from study to study ${ }^{9,14-21}$. Karagiannidis et al. tested the maximal isometric contractions of the knee flexors 1 year after ACL reconstruction with an ST tendon graft in 8 cases and 8 matched controls and found that ACL reconstruction has an effect on ST muscle belly but effect on force generation capacity is rather limited 22 . A retrospective study conducted by Ardern et al. ${ }^{14}$ did not prove any difference in terms of objective knee stability, subjective scores, isometric and isokinetic strength at two years from the surgery. Barenius et al. ${ }^{15}$ confirmed the absence of any significant difference related to $A C L$ reconstruction with hamstrings tendons comparing the one-tendon technique to the two-tendons technique. Tashiro et al. ${ }^{20}$ did not show any difference analyzing the clinical outcomes comparing the use of the quadrupled semitendinosus and the use of the tripled gracilis and semitendinosus. However, patients from the GST group suffered a significant isokinetic strength deficit in flexion in comparison to ST group at six months postoperatively. The same study described an isokinetic strength deficit at the deepest angle of flexion, for both groups, but more obvious in GST groups at 18 months postopera- tively. Adachi et al. ${ }^{23}$ demonstrated that harvesting semitendinosus and gracilis, compared to semitendinosus alone and allograft, can induce a loss of muscle strength at the deep flexion angle. Other Authors ${ }^{9}$, 19,24 proved a reduction in internal rotation strength when the gracilis was harvested. In a recent metaanalysis, Sharma et al. ${ }^{25}$ concluded that the additional harvest of the gracilis contributed to isokinetic strength loss at $60 \%$ s and to isometric strength loss at $90^{\circ}$ and at $105-110^{\circ}$ of flexion without other clinical variation. Table $\mathrm{V}$ summarizes the principal results of the previous studies.

This study has various limitations. It is a retrospective study with a limited number of patients and its structure did not allow the comparison between clinical and instrumental preoperative data and the postoperative ones. Isokinetic test was executed at the sixth month postoperatively, not measuring the internal rotation strength. The isokinetic test would have to be repeated in prone position in order to evaluate the strength with the deepest degree of flexion. The internal rotation strength, according to some Authors ${ }^{26}$, can be affected by regeneration of tendons. Therefore, it would have been interesting to know whether leaving the gracilis tendon function intact, internal rotation force increased. Unfortunately, this study cannot answer to this question. The study does not allow consideration about the fixation efficacy and the be- 
Table V. Results of the literature concerning the muscle strength in hamstring graft selection. ST, semitendinosus; GST, gracilis + semitendinosus; 2, double; 3, tripled; 4, quadrupled; CO, clinical outcomes; $\%$, degree per second; RCT, randomized controlled trial.

\begin{tabular}{|c|c|c|c|c|c|c|}
\hline Authors & Year & Study design & Cohort & Type of graft & Clinical evaluation & $\begin{array}{l}\text { Difference in Strength } \\
\text { recovery }\end{array}$ \\
\hline $\begin{array}{l}\text { Segawa } \\
\text { et al. }\end{array}$ & 2002 & $\begin{array}{l}\text { Prospective cohort, } \\
\text { level } 2\end{array}$ & 62 & $\begin{array}{l}3 \mathrm{ST} / 4 \mathrm{ST} \text { vs } \\
2 \mathrm{GST}\end{array}$ & No difference in CO & Reduced in 2 GST group \\
\hline $\begin{array}{l}\text { Tashiro } \\
\text { et al. }\end{array}$ & 2003 & RCT, level 1 & 85 & 4ST vs 3GST & $\begin{array}{l}\text { No difference in } \\
\text { stability and activity } \\
\text { level }\end{array}$ & $\begin{array}{l}\text { Reduction in isokinetic } \\
\text { strength in } 3 G S T \text { group } \\
\text { Reduction in torque at } 70^{\circ} \\
\text { and } 110^{\circ} \text { flexion in } 3 G S T \\
\text { group }\end{array}$ \\
\hline $\begin{array}{l}\text { Gobbi } \\
\text { et al. }\end{array}$ & 2005 & RCT, level 1 & 97 & 4ST vs 2GST & $\begin{array}{l}\text { No difference in CO } \\
\text { and self-evaluation } \\
\text { score }\end{array}$ & $\begin{array}{l}\text { Isokinetic strength loss in } \\
\text { Internal rotation in } 2 \mathrm{GST} \\
\text { group }\end{array}$ \\
\hline $\begin{array}{l}\text { Ardern } \\
\text { et al. }\end{array}$ & 2010 & $\begin{array}{l}\text { Retrospective cohort } \\
\text { study, level } 3\end{array}$ & 50 & 4ST vs 2GST & $\begin{array}{l}\text { No difference in } \\
\text { clinical evaluation }\end{array}$ & No differences \\
\hline $\begin{array}{l}\text { Yosmaoglu } \\
\text { et al. }\end{array}$ & 2011 & $\begin{array}{l}\text { Prospective chort, } \\
\text { level } 2\end{array}$ & 46 & ST vs GST & $\begin{array}{l}\text { No in side-to-side } \\
\text { difference in anterior } \\
\text { tibial translation }\end{array}$ & $\begin{array}{l}\text { Higher side-to-side } \\
\text { difference in knee flexor } \\
\text { torque in GST at } 60 \% \mathrm{~s}\end{array}$ \\
\hline $\begin{array}{l}\text { Barenius } \\
\text { et al. }\end{array}$ & 2013 & $\begin{array}{l}\text { Retrospective cohort } \\
\text { study, level } 3\end{array}$ & 20 & 4ST vs 2GST & $\begin{array}{l}\text { No difference in } \\
\text { stability and CO }\end{array}$ & No differences \\
\hline $\begin{array}{l}\text { Inagaki } \\
\text { et al. }\end{array}$ & 2013 & $\begin{array}{l}\text { Prospective chort, } \\
\text { level } 2\end{array}$ & 120 & $\begin{array}{l}\text { Double-bundle } \\
\text { technique: } \\
\text { 4ST vs } 2 \text { GST }\end{array}$ & $\begin{array}{l}\text { No difference in CO } \\
\text { and subjective score }\end{array}$ & No differences \\
\hline $\begin{array}{l}\text { Karimi } \\
\text { et al. }\end{array}$ & 2015 & RCT, level 1 & 119 & $4 \mathrm{ST}$ vs $2 \mathrm{GST}$ & $\begin{array}{l}\text { No difference in } \\
\text { stability and CO }\end{array}$ & No differences \\
\hline $\begin{array}{l}\text { Kentel } \\
\text { et al. }\end{array}$ & 2015 & $\begin{array}{l}\text { Retrospective cohort } \\
\text { study, level } 3\end{array}$ & 60 & $\begin{array}{l}\text { 2ST vs GST vs } \\
\text { control group }\end{array}$ & Not assessed & $\begin{array}{l}\text { No strength differences. } \\
\text { Influence of gracilis } \\
\text { harvest in the deep internal } \\
\text { shin-rotation torque. }\end{array}$ \\
\hline $\begin{array}{l}\text { Sharma } \\
\text { et al. }\end{array}$ & 2016 & $\begin{array}{l}\text { Systematic Review } \\
\text { of level I-III studies, } \\
\text { level III }\end{array}$ & $\begin{array}{c}12 \\
\text { studies }\end{array}$ & $\begin{array}{l}\text { ST-harvest vs } \\
\text { GST-harvest } \\
\text { (Various folding) }\end{array}$ & $\begin{array}{l}\text { No difference in } \\
\text { stability and CO }\end{array}$ & $\begin{array}{l}\text { Active knee flexion loss. } \\
\text { Reduced strength at } 60 \% \mathrm{~s} \\
\text { in GST groups }\end{array}$ \\
\hline
\end{tabular}

havior of the tunnel in the long period. While Zysk et al. reported unsatisfactory results of the tripled semitendinosus with the Endobutton fixation on the femoral side due to a high incidence of bone tunnel enlargement ${ }^{27}$, Barber supported the effectiveness of Bioscrew fixation of the tripled semitendinosus-cancellous bone graft ACL reconstruction ${ }^{28}$ and Srinivas reported that femoral tunnel and tibial tunnel widening vary with different methods of fixation ${ }^{29}$. Finally, the level of the return to sport could have evaluated with more specific tests ${ }^{30}$.

This study slightly differs from the above mentioned studies because a tripled semitendinosus graft has been used instead of a quadrupled tendon graft (4ST). One of the limits of 4ST is the need of a substantial length of the tendon ${ }^{15}$. ST3 procedure requires a minimum of $80 \mathrm{~mm}$ for the prepared harvest, corresponding to a minimal length of $240 \mathrm{~mm}$ for the tendon. This is commonly reached in the population and therefore a wide application of this type of graft is possible. Concerns about the graft resistance are weak: the mechanical resistance of the tripled semitendinosus graft, was already demonstrated by Stapleton et al., who compared the initial biomechanical properties of currently accepted reconstruction methods, included the ST3, tested using lower extremity cadaveric specimens. All grafts showed similar initial absolute strength and the values were adequate for ACL reconstruction with safety ${ }^{31}$. Fabbri et al. biomechanically tested three different graft configurations and showed that the tripled configuration had sufficient biomechanical characteristics to withstand the loads experienced during early rehabilitation ${ }^{32}$.

\section{Conclusion}

The tripled semitendinosus graft is a valid option in primary ACL reconstruction: it is potentially less inva- 
Tripled semitendinosus with single harvesting is as effective but less invasive compared to standard gracilissemitendinosus harvesting

sive and does not lead to any statistically significant disadvantage compared to the harvesting of the two tendons. Moreover, saving the gracilis tendon is sometimes associated with a minor deficit of strength in flexion.

\section{Conflict of interest}

The Authors have no conflicts of interest.

\section{References}

1. Budny J, Fox J, Rauh M, Fineberg M. Emerging Trends in Anterior Cruciate Ligament Reconstruction. J Knee Surg. 2017;30:63-69.

2. Samuelsson K, Andersson D, Ahldén M, Fu FH, Musahl V, Karlsson J. Trends in surgeon preferences on anterior cruciate ligament reconstructive techniques. Clin Sports Med. 2013;32:111-126.

3. Mothadi NG, Chan DS, Dainty KN, Whelan DB. Patellar tendon versus hamstring tendon autograft for anterior cruciate ligament rupture in adults. Cochrane Database Syst. Rev. 2011;7:CD005960.

4. Aglietti P, Giron F, Buzzi R, Biddau F, Sasso F. Anterior cruciate ligament reconstruction: bone-patellar tendon-bone compared with double semitendinosus and gracilis tendon grafts. A prospective, randomized clinical trial. J Bone Joint Surg. 2004;86-A:2143-55.

5. West RV, Harner CD. Graft selection in anterior cruciate ligament reconstruction. J Am Acad Orthop Surg. 2005;13:197207.

6. Nakamura N, Horibe S, Sasaki S, Kitaguchi T, Tagami M, Mitsuoka $\mathrm{T}$, et al. Evaluation of active knee flexion and hamstring strength after anterior cruciate ligament reconstruction using hamstring tendons. Arthroscopy. 2002;18: 598-602.

7. Nomura Y, Kuramochi R, Fukubayashi T. Evaluation of hamstring muscle strength and morphology after anterior cruciate ligament reconstruction. Scand J Med Sci Sports. 2015;25:301-307

8. Kim JG, Yang SJ, Lee YS, Shim JC, Ra HJ, Choi JY. The effects of hamstring harvesting on outcomes in anterior cruciate ligamentreconstructed patients: A comparative study between hamstring-harvested and -unharvested patients. J Arthrosc Relat Surg. 2011;27:1226-1234.

9. Gobbi A, Domzalski M, Pascual J, Zanazzo M. Hamstring anterior cruciate ligament reconstruction: Is it necessary to sacrifice the gracilis? J Arthrosc Relat Surg. 2005;21:275280.

10. Padulo J, Oliva F, Frizziero A, Maffulli N. Muscles, Ligaments and Tendons Journal - Basic principles and recommendations in clinical and field science research: 2016 update. MLTJ. 2016;6(1):1-5.

11. Ardern CL. Anterior Cruciate Ligament Reconstruction-Not Exactly a One-Way Ticket Back to the Preinjury Level: A Review of Contextual Factors Affecting Return to Sport After Surgery. Sports Health. 2015;7(3):224-230.

12. Ardern CL, Taylor NF, Feller JA, Webster KE. Fifty-five per cent return to competitive sport following anterior cruciate ligament reconstruction surgery: an updated systematic review and meta-analysis including aspects of physical functioning and contextual factors. Br J Sports Med. 2014;48: 1543-1552.

13. Notarnicola A, Maccagnano G, Barletta F, Ascatigno L, Astuto L, Panella A, Tafuri S, Moretti B. Returning to sport af- ter anterior cruciate ligament reconstruction in amateur sports men: a retrospective study. Muscles Ligaments Tendons J. 2016;12-6(4):486-491.

14. Ardern CL, Webster KE, Taylor NF, Feller JA. Hamstring Strength Recovery After Hamstring Tendon Harvest for Anterior Cruciate Ligament Reconstruction: A Comparison Between Graft Types. Arthroscopy. 2010;26:462-469.

15. Barenius B, Webster WK, McClelland J, Feller J. Hamstring tendon anterior cruciate ligament reconstruction: Does gracilis tendon harvest matter? Int Orthop. 2013;37:207-212.

16. Inagaki Y, Kondo E, Kitamura N, Onodera J, Yagi T, Tanaka $Y$, et al. Prospective clinical comparisons of semitendinosus versus semitendinosus and gracilis tendon autografts for anatomic double-bundle anterior cruciate ligament reconstruction. J Orthop Sci. 2013;18:754-761.

17. Karimi-Mobarakeh M, Mardani-Kivi M, Mortazavi A, SahebEkhtiari K, Hashemi-Motlagh K. Role of gracilis harvesting in four-strand hamstring tendon anterior cruciate ligament reconstruction: a double-blinded prospective randomized clinical trial. Knee Surg Sports Traumatol Arthrosc. 2015 23:1086-1091.

18. Królikowska A, Czamara A, Kentel M. Does Gracilis Tendon Harvest During ACL Reconstruction with a Hamstring $\mathrm{Au}$ tograft Affect Torque of Muscles Responsible for Shin Rotation? Med Sci Monit. 2015;21:2084-2093.

19. Segawa H, Omori G, Koga $Y$, Kameo T, lida S, Tanaka M Rotational muscle strength of the limb after anterior cruciate ligament reconstruction using semitendinosus and gracilis tendon. Arthroscopy. 2002;18:177-182.

20. Tashiro T, Kurosawa H, Kawakami A, Hikita A, Fukui N. Influence of medial hamstring tendon harvest on knee flexor strength after anterior cruciate ligament reconstruction. A detailed evaluation with comparison of single- and doubletendon harvest. Am J Sports Med. 2003;31:522-529.

21. Yosmaoglu HB, Baltaci G, Ozer H, Atay A. Effects of additional gracilis tendon harvest on muscle torque, motor coordination, and knee laxity in ACL reconstruction. Knee Surgery Sport Traumatol Arthrosc. 2011;19:1287-1292.

22. Karagiannidis E, Kellis E, Galanis N, Vasilios B. Semitendinosus muscle architecture during maximum isometric contractions in individuals with anterior cruciate ligament reconstruction and controls. Muscles Ligaments Tendons J. 2017;10-7(1):147-151.

23. Adachi N, Ochi M, Uchio Y, Sakai Y, Kuriwaka M, Fujihara A. Harvesting hamstring tendons for $A C L$ reconstruction influences postoperative hamstring muscle performance. Arch Orthop Trauma Surg. 2003;123:460-465.

24. Petersen W, Taheri P, Forkel P, Zantop T. Return to play following ACL reconstruction: a systematic review about strength deficits. Arch Orthop Trauma Surg. 2014;134:14171428.

25. Sharma A, Flanigan DC, Randall K, Magnussen RA. Does Gracilis Preservation Matter in Anterior Cruciate Ligament Reconstruction? A Systematic Review. Arthroscopy. 2016; 32:1165-1173

26. Ferretti $A$, Vadalà A, De Carli A, Argento G, Conteduca F, Severini G. Minimizing internal rotation strength deficit after use of semitendinosus for anterior cruciate ligament reconstruction: a modified harvesting technique. Arthroscopy. 2008;24(7):786-795.

27. Zysk SP, Krüger A, Baur A, Veihelmann A, Refior HJ. Tripled semitendinosus anterior cruciate ligament reconstruction with Endobutton fixation. Acta Orthop Scand. 2000;71:381 386.

28. Barber FA. Tripled semitendinosus-cancellous bone anterior cruciate ligament reconstruction with bioscrew fixation. Arthroscopy. 1999;15:360-367.

29. Srinivas DK. Femoral and Tibial Tunnel Widening following 
Anterior Cruciate Ligament Reconstruction using Various Modalities of Fixation: A Prospective Observational Study. J Clin Diagnostic Res. 2016;10:10-12.

30. Bisciotti GN, Quaglia A, Belli A, Carimati G, Volpi P. Return to sports after $A C L$ reconstruction: a new functional test protocol. Muscles Ligaments Tendons J. 2016;12-6(4):499509.
31. Stapleton TR, Curd DT, Baker CL. Initial biomechanical properties of anterior cruciate ligament reconstruction autografts. J South Orthop Assoc. 1999;8:173-180.

32. Fabbri M, Monaco E, Lanzetti RM, Perugia D, Guzzini M, Labianca $\mathrm{L}$, et al. Single harvesting in the all-inside graft-link technique: is the graft length crucial for success? A biomechanical study. J Orthop Traumatol. 2017;18:17-22. 